\title{
Analysis of soil parameters causing dieback in Sundarbans
}

\author{
Awal, Mohd Abdul \\ Founder \& Chief Advisor, Health \& Pollution Research Farm, 23-09-37 Avenue, Apt, No: 1, Long Island City, New York, USA
}

\section{Email address:}

abdul_awal2004@yahoo.com

\section{To cite this article:}

Awal, Mohd Abdul. Analysis of Soil Parameters Causing Dieback in Sundarbans. American Journal of Environmental Protection. Vol. 3, No. 3, 2014, pp. 162-171. doi: 10.11648/j.ajep.20140303.18

\begin{abstract}
A Sundarbans mangrove in Bangladesh is facing tremendous problems of heavy metal contaminations in soil (Awal, 20014). The present work has explored some of the possible parameters involved, focussing particularly on the relationship between the amount of top-dying in different places and the concentrations of a number of chemical parameters present in the soil, in order to test the hypothesis that chemical pollution might be responsible (Awal, 2014). Other factors such as the $\mathrm{pH}$, salinity and nutrient status were also assessed (Awal 2014). Nine plots were selected for sampling of soil in order to categorise different areas in terms of their intensity of top-dying (Awal 2007). 63 soil samples were tested, mainly by ICPMS, to investigate certain parameters of the soil such as $\mathrm{Sn}$, Exchangeable $\mathrm{K}$, Soil $\mathrm{pH}, \mathrm{Pb}, \mathrm{Zn}$, Ni, EC, soil nutrients, soil moisture content, and elemental concentrations of 32 other elements (Awal 2009). The vegetation structure was assessed in terms of tree height, bole diameter, species present, and regeneration status; and the intensity of top-dying within the plots was recorded on a rank scale. Most of the elements studied had no significant correlation with the top dying of Heritiera fomes. However, $\mathrm{Sn}$, Exchangeable $\mathrm{K}$, and soil $\mathrm{pH}$ were significantly related, and three elements, namely $\mathrm{Pb}$, $\mathrm{Zn}, \mathrm{Ni}$, were also close to significance (Awal, 2007). Sn concentration is negatively associated with top dying. Soil pH varied significantly in the different plots (Awal 2007). Exchangeable $\mathrm{K}$ was positively associated with the tree diameter whether the top dying was severe or mild (Awal 2007). However, the present results have showed that Sn, Exchangeable $\mathrm{K}$, soil $\mathrm{pH}, \mathrm{Pb}, \mathrm{Zn}$ and $\mathrm{Ni}$ could be directly linked with top-dying of Heritiera fomes (Sundri) in Sundarbans, probably particularly by weakening the vigour of the trees and allowing other parameters such as pathological agents to attack the plants (Awal, 2007).
\end{abstract}

Keywords: Environmental Parameters, Environmental Factors, Causal Parameters, Soil Parameters, Heritiera fomes, Heavy Metal Concentrations in Soil of Sundarbans, Dieback of Sundarbans, Sundarbans, Top-dying

\section{Introduction}

The Sundarbans is the largest, ecologically and biologically richest, and most extensive mangrove forest in the world. Ecosystems of this world heritage site supports versatile interactions and correlations and relationships among its vertebrates and invertebrates, flora, fauna, aquatic organisms, marine lives, wildlife, fishes, birds, natural habitats, micro soil and water relationship supports this largest wildlife habitats (Awal, 2007 and 2009). Heritiera fomes (Sundri) tree is the most important ecologically powerful and economically worth tree species in the Sundarbans (Awal 2007). However, a killer disease (dieback) of $H$. fomes in Sundarbans is affecting millions of the trees and destroying its originality of ecosystems
(Awal 2014). The present research, for the first time in Bangladesh, shows very interesting correlations between soil and top-dying index values in soil of Sundarbans (Awal, 2014). Sources of environmental pollution and contamination of heavy metals in Sundarbans could be mainly from upland rivers, water basins, Mongla port, Kornafully Newsprint mills, various match box-making factories, hardboard factories, coastal development, shipping, oil, and in some areas the discharge of toxic wastes, and from Farakka barrage, and other areas of Bangladesh and Indian territories (Awal, M.A. 2007; UNESCAP, 1988). In addition, due to chemical pollution in soil and human destruction, abolishing rates of Sundarbans has presently accelerated mostly due to heavy metal contamination in soil (Awal, M.A. 2007). Also, there were 
157 major oil spills in tropical seas between 1974 and 1990 which is also threatening sources for the ecological catastrophe (Burns et al., 1993). Deep mud coastal habitats may take 20 years or more to recover from the toxic effects of such oil spills (Phillips, 1994). The Sundarbans is therefore a dynamic natural resource, which could be affected by changing chemical and physical properties of soils including other soil parameters which could affect forest growth, and abolishing ecosystems of Sundarbans in Bangladesh (Awal, 2014).

\subsection{Soil}

The Sundarbans soils contain a large amount of clay and silt content, and have been got allochthonously from deltaic floodplain alluviums and autochthonously from tidal marsh materials consisting mainly of organic matter (peat deposition) and, to a lesser extent, from bicarbonates from shell-farming marine / estuarine organisms (Choudhury, 1962). The Sundarban soil is classified as Typic Haplaquents (Anon, 1975; Gopalswamy and Chowdhury, 1973). In the eastern part of Sundarbans the surface soil is soft and fertile, whereas it is harder and less suitable for tree growth in the west (Choudhury, 1968). The present result shows the moisture content of soil is quite low with the average of $21.36 \%$ by wet weight but nowhere exceeding $30.25 \%$ by wet weight (Awal, 2014). This contrasts with the moisture content thought to be necessary for mangroves of $47 \%$ minimum, usually much higher (Awal 2007).

\subsection{Hydrology and Tides}

A large part of the Sundarban stays above tidal level during the lean season, while only a part is become covered with water during the spring high tides and a small part in the South and West is tidally made a place become covered with water throughout the year. However, the whole of the Sundarbans becomes submerged during high rain as tide that falls during April to October, when it rains a lot in Bangladesh, India and Southeast Asian countries. The Sundarbans are criss-crossed where a pattern made up of more or less straight lines by a network of interconnecting channels (Islam, 2003) and the main rivers are the Baleswar, Passur, Sibsa, Kobadak, Jamuna and Raimangal. The Baleswar and Passur rivers are linked with the Ganges through the Gorai- Modhumati, and the Arial khan rivers where connected $\mathrm{d}$ two or more rivers together in Bangladesh (Awal, 2007). The Sibsa and Kobadak rivers are not linked with the main flow of the Ganges during the lean season (Awal 2007). The Baleswar, washing the eastern fringe of the Sundarbans, receives the bulk of the Ganges water while the Passur shares only a few cusecs during the lean season (Awal, 2007; Own observation, 1993-97).

\subsection{Salinity}

Salinity variation showed a seasonal cycle, where soil salinity remained between 2000 and 4500 micro mohs in most parts of the Sundarbans during March to May (Anon, 1972). Karim, 1988; and Bhuiyan, 1994 reported to give information about recent problems and events of top-dying that salinity concentration in the eastern part of the Sundarbans is the lowest and that concentration of salinity in the western part is the highest, but moderate salinity concentration is found in the central part of the Sundarbans (Awal, 2007). Bangladesh Forest Research Institute (BFRI), during 1990 to 1994 , conducted mean monthly soil salinity sampling among the compartments 28 (Chandpai), 36 (Kassiabad), and 46 (Burigoalini), and recorded 3168.44, 4590.15 , and 6579.79 micro mhos respectively to carryout a particular process specially in order to get accurate information or facts. After the dry season (March to May), the soil salinity generally remains below 2000 micro mohs in Sundarbans (Awal, 2007).

\subsection{Vegetation}

Based on protection for the diversity of its resources, the Sundarban was declared as a reserve in 1876 and also declared as a world Heritage Site in 1997 to state officially (UNESCO, 1997). Being situated in an important transition zone, this largest ecological unit was very rich in species and agreed with the greatest diversity of flora. Sundri (Heritiera fomes) and tiger (Panthera tigris) have been listed to mention as endangered in Bangladesh from early in the twentieth century (Champion, 1936). H. fomes is adapted to the wet swampy condition of the Sundarbans to be suitable in different situations within this particular and sensitive ecosystem by virtue of its leaves having partly xerophytic adaptations, regular inundation and plentiful pneumatophores which help cope with the saline swamps of the Sundarbans (Awal, 2007).

\subsection{Effluent discharge}

In case of Thailand, effluent discharge from intensive shrimp farming has been put at 1.29 billion cubic meters of effluent per year (FAO Report, 1997), although it has not been assessed in Bangladesh. Effluent discharge is a problem of Sundarbans (Personal communication Mongla Port Authority, Khulna, 1996). A large number of industries are discharging untreated effluents directly into the river at Khulna to contaminate soil which is carried down to the Sundarbans forest floor (Awal, 2007). The polluting industries are Khulna Newsprint Mill (KNM), Hardboard Mills, some match factories, Mongla port areas, all rivers, channels, and fish processing units, Goalpara power station, some Jute mills and Khulna shipyard (Awal, 2007). KNM alone continuously discharge nearly $4500 \mathrm{~m}^{3} /$ ha of waste water containing high levels of suspended solids (300$500 \mathrm{mg} / \mathrm{l}$ ) and sulphur compounds (UN-ESCAP, 1987). Moreover, resuspension of soil dredging material for port development is a potential threat to the Sundarbans due to long lasting toxicological effects from chemical or heavy metal pollution (Awal, 2014). 


\subsection{Soil factors}

Heavy metal concentrations in the Sundarbans soil had not yet been measured systematically (Awal, 2007), despite the potential contamination from effluent discharged (Awal, 2007). The information of heavy metals in the soil with possible noticeable effects upon the Sundarbans Reserved Forests was negligible and still is scanty (Awal, 2007). All kinds of wastes or pollutants dumped into the rivers into untidy way which are deposited into the soil of Sundarbans that can grow a change of physical characteristics of the soils and ecosystems naturally (Awal, 2007). Mangrove plants are generally thought as about filters for many pollutants, but such materials can be passed along a foodchain, ultimately with a potential of attaining unacceptable high levels in species used by humans (Awal, 2007).

\section{Methodology}

\subsection{Field sampling methods}

Fieldwork was performed between October 2003 and March 2004. Sampling was from the area of the Sundarbans near Chandpai, which is the area most accessible to people and also potentially the one that is most polluted. Three areas (termed 'compartments') from this region were selected (numbers 26, 28 and 31) because they were believed to represent a range of severity of topdying disease as well as of human activities, as outlined in Awal et al. (2009). Within each of the three compartments, sampling of vegetation, mangrove sediment and water took place within three $20 \mathrm{~m} \times 20 \mathrm{~m}$ plots, chosen to reflect a range of top-dying intensities (high, medium and low for that area). The sampling was conducted in a randomised block design, in that a plot was sited within a particular top-dying intensity block, but the precise location of that plot was randomised so as not to bias the detailed data collection. Therefore a total of nine plots was sampled. It should be noted that the material making up the mangrove sediments will include marine, coastal and freshwater deltaic sediments as well as biological material such as tree litter-fall. The relative importance of these sources will depend to a great extent on the patterns of river discharge (Dyer, 1986) and the extent of tidal inundation, and will also therefore vary spatially throughout the Sundarbans.

\subsection{Soil sampling methods}

Three selected compartments, a total of nine plots of $20 \mathrm{~m}$ x $20 \mathrm{~m}$ were selected. From each of these plots, seven soil samples were collected; one from the centre of the plot, four (one each) from all the corners, and two from the middle sides of the plot. Therefore a total of 63 soil samples were taken. Soil samples were collected from 0-30 cm soil depth by using a stainless steel spatula and steel cylinder $(d=5.25 \mathrm{~cm})$, and all soil samples were kept in sealed plastic bags. Marking and labelling was performed with a detailed description of the selected sampling site on both the soil- plastic bags, and preserved in portable coolers until arrival at the laboratory for chemical analysis by ICPMS. This field sampling method followed the W.H.O, U.K, and E.P.A systems of standard laboratory and field sampling principles, rules and regulations.

\subsection{Statistical Analysis}

Initial statistical analysis of quantitative data, particularly of the elemental concentrations, consisted of calculation of arithmetic means, standard deviations and standard error values for each variable separately. Data on the severity of top-dying for each tree in a plot, which had been recorded as ' not affected', 'mildly affected', 'moderately affected', and 'highly affected', were converted into a four-point scale (0-3), so that they could be summed and an average (median) could be determined for each plot, thus producing an index based on ranked data. Comparisons of the strength of relationship between two variables were assessed by correlation: the Pearson's product-moment correlation coefficient where both variables were fully quantitative or the Spearman's rank correlation coefficient where the top-dying index was one of the variables. In the case of the Spearman's coefficient, the probability of the outcome was determined by using the approximation to a t-statistic appropriate to these tests (Sokal and Rohlf, 1981). Occasionally, a Pearson's correlation coefficient was calculated where top-dying was one of the variables, in order to check on the extent of the difference between the rank and quantitative versions for these data (Awal, 2007).

Data on frequencies of seedlings or saplings in each of the plots and compartments were tested by $x^{2}$ contingency table analysis to determine whether there was an association between the selected plot type (severely, moderately or little affected by top-dying) and the three chosen compartments. A similar consideration of the different compartments as comprising one factor, and the plot type as a second, was used to test the pattern of elemental concentrations and other variables by a 2 -factor analysis of variance test with replication. This allows an assessment of the significance, not only of the two factors separately but also of the interaction term linking the two factors. It should be noted that the plot type was not a strictly controlled factor, since the three categories of topdying intensity were relative to each other within any one compartment and might not have been exactly equivalent between the three categories; interpretation of the results from these tests therefore needs to bear this in mind.

MINITAB Release 14 Statistical Software has been used for windows on CD-ROM, 2004 edition for all data analysis, both statistical and graphical, except for those produced automatically by the Excel package attached to the ICPMS. 


\section{Results}

Values from the chemical analyses by ICPMS of the elemental composition of soils in the different compartments and plots are presented in a series of tables (3.13 to 3. 22) owing to the large number of data values involved.

\subsection{Comparisons of Parameters by Correlation Analysis}

The relationship between soil characteristics and the amount of top-dying

A primary objective of the present work is to establish whether the concentrations of the various chemical elements, or other soil parameters, are having an influence on the amount of top-dying believed to exist in the different plots. To this end, correlations have been found out the exact details or facts about the relationship between the top-dying index and the various parameters. The various heavy metal concentrations, arising from the ICPMS work, were tested using Spearman's rank correlation coefficient, with the results included in Table 3.3. There were no elements which gave a significant correlation with the index of top-dying, although $\mathrm{Sn}$ gave a (negative) correlation which was close to significant $(p<0.1)$. It is clear that, within the scope of the present samples and data collected, there is no indication that heavy metal concentrations are influencing the amount of top-dying, with the possible exception of $\mathrm{Sn}$.

The Spearman's correlation was used here because the top-dying data are based on an index, and probably not meeting all the assumptions of truly parametric data. However, the elemental concentrations are fully quantitative data, and using this statistic will result in information loss. Therefore, it was decided to test the $\mathrm{Sn}$ data, as well as data for a few other heavy metals (those with the strongest correlations in the previous tests), using the Pearson's correlation coefficient instead in order to assess how different the results would be if the data were treated as fully quantitative which is connected with amount rather than with the quality or nature of top-dying. The results from these tests, as well as the tests on other soil and water parameters, are shown in

Table 3.4. The result for $\mathrm{Sn}$ has changed probability slightly, but sufficiently to become significant, while the result for $\mathrm{Pb}$ has moved to becoming less than $10 \%$ significance. All other results were clearly non-significant. Consequently it may be concluded that there is very little in terms of chemical parameters that shows any clear relationship with the amount of top-dying, with $\mathrm{Sn}$ and possibly $\mathrm{Pb}$ being the only elements with any notable effect. It may also be concluded that, while use of the quantitative Pearson's correlation coefficient slightly increases the significance of the results, it does not substantially change the conclusions that arose from using the rank correlation technique.
Table 3.1. Pearson's correlation coefficient values from assessing the relationship between tree height $(m)$ and the concentrations of various elements (in ppb) or other chemical parameters. Key to symbols: N.S. = not significant, $p>0.05 ; *=0.05>p>0.01, p<0.1=$ not significant, but close to it.

\begin{tabular}{llll}
\hline $\begin{array}{l}\text { Name of elements } \\
\text { being correlated with } \\
\text { tree height (m) }\end{array}$ & $\begin{array}{l}\text { Value of r } \\
\text { (with 7df) }\end{array}$ & $\begin{array}{l}\text { Probability } \\
\text { (P-value) }\end{array}$ & Significance \\
\hline Soil EC. & 0.171 & 0.661 & NS \\
Nickel (Ni) & -0.438 & 0.238 & N.S \\
Lead (Pb) & 0.392 & 0.297 & N.S \\
Soil pH & 0.181 & 0.642 & N.S \\
Water pH & -0.280 & 0.466 & N.S \\
$\begin{array}{l}\text { Exchangeable } \\
\text { Potassium (K) }\end{array}$ & 0.576 & 0.105 & NS \\
$\begin{array}{l}\text { Exchangeable Sodium } \\
\text { Na) }\end{array}$ & 0.617 & 0.077 & p $<0.1$ \\
$\begin{array}{l}\text { Soluble Sodium } \\
\text { Na) }\end{array}$ & -0.012 & 0.976 & NS \\
Soil Sulphur (S) & 0.233 & 0.547 & NS \\
Tin ( Sn ) & 0.086 & 0.826 & N.S \\
Zinc ( Zn ) & 0.219 & 0.571 & N.S \\
\hline
\end{tabular}

Table 3.2. Pearson's correlation coefficient values from assessing the relationship between tree diameter $(\mathrm{cm})$ and the concentrations of various elements (in ppb). Key to symbols: N.S. = not significant, $p>0.05 ; *=$ $0.05>p>0.01, p<0.1=$ not significant, but close to it.

\begin{tabular}{llll}
\hline $\begin{array}{l}\text { Name of elements } \\
\text { being correlated with } \\
\text { tree diameter }\end{array}$ & $\begin{array}{l}\text { Value of } \mathbf{r} \\
\text { (with 7df) }\end{array}$ & $\begin{array}{l}\text { Probability } \\
\text { value }\end{array}$ & Significance \\
\hline $\begin{array}{l}\text { Nickel }(\mathrm{Ni}) \\
\text { Lead }(\mathrm{Pb})\end{array}$ & -0.017 & 0.965 & N.S \\
$\mathrm{pH}$ of Soil & -0.655 & 0.056 & $(\mathrm{p}<0.1)$ \\
$\mathrm{pH}$ of water & 0.452 & 0.221 & N.S \\
$\begin{array}{l}\text { Exchangeable } \\
\text { Potassium (K) }\end{array}$ & 0.540 & 0.133 & N.S \\
$\begin{array}{l}\text { Exchangeable Sodium } \\
\text { Na) }\end{array}$ & -0.672 & 0.047 & $*$ \\
Soluble Sodium (Na) & -0.656 & 0.055 & $(\mathrm{p}<0.1)$ \\
Soil Sulphur (S) & -0.466 & 0.206 & NS \\
Sn (Tin) & $\mathbf{- 0 . 2 5 8}$ & $\mathbf{0 . 5 0 2}$ & N.S \\
Zn (Zinc) & -0.232 & 0.548 & N.S \\
\hline
\end{tabular}

Table 3.3. Spearman's rank correlation coefficient analysis, comparing the concentration of individual chemical elements in the soil with the index of top dying for each plot level of significance was indicated by approximation to t-test results ( in all cases, $N=9, d f=7$ ), N.S= Not Significant.

\begin{tabular}{ccccc}
\hline $\begin{array}{c}\text { Name of the } \\
\text { elements }\end{array}$ & $\mathbf{r}_{\text {s }}$-value & t-value & Probability & Significance \\
\hline $\mathrm{Al}$ & 0.020 & 0.052 & $>0.05$ & N.S. \\
$\mathrm{As}$ & 0.040 & 0.105 & $>0.05$ & N.S. \\
$\mathrm{B}$ & 0.200 & 0.540 & $>0.05$ & N.S. \\
$\mathrm{Ba}$ & 0.250 & 0.683 & $>0.05$ & N.S. \\
$\mathrm{Bi}$ & 0.300 & 0.831 & $>0.05$ & N.S. \\
\hline
\end{tabular}




\begin{tabular}{|c|c|c|c|c|}
\hline $\begin{array}{l}\text { Name of the } \\
\text { elements }\end{array}$ & $\mathbf{r}_{\mathrm{s}}$-value & t-value & Probability & Significance \\
\hline $\mathrm{Ca}$ & 0.280 & 0.804 & $>0.05$ & N.S. \\
\hline $\mathrm{Cd}$ & 0.260 & 0.712 & $>0.05$ & N.S. \\
\hline Co & 0.390 & 1.120 & $>0.05$ & N.S. \\
\hline $\mathrm{Cr}$ & 0.234 & 0.636 & $>0.05$ & N.S. \\
\hline $\mathrm{Cu}$ & 0.330 & 0.924 & $>0.05$ & N.S. \\
\hline $\mathrm{Fe}$ & 0.034 & 0.089 & $>0.05$ & N.S. \\
\hline $\mathrm{Hg}$ & 0.017 & 0.044 & $>0.05$ & N.S. \\
\hline In & -0.250 & -0.683 & $>0.05$ & N.S. \\
\hline K & 0.084 & 0.223 & $>0.05$ & N.S. \\
\hline $\mathrm{Mg}$ & 0.250 & 0.683 & $>0.05$ & N.S. \\
\hline Mo & 0.000 & 0.000 & $>0.05$ & N.S. \\
\hline $\mathrm{Mn}$ & 0.380 & 1.086 & $>0.05$ & N.S. \\
\hline $\mathrm{Na}$ & 0.320 & 0.904 & $>0.05$ & N.S. \\
\hline $\mathrm{Ni}$ & 0.466 & 1.393 & $>0.05$ & N.S. \\
\hline $\mathrm{P}$ & -0.016 & -0.042 & $>0.05$ & N.S. \\
\hline $\mathrm{Pb}$ & 0.516 & 1.593 & $>0.05$ & N.S. \\
\hline $\mathrm{Rb}$ & 0.084 & 0.223 & $>0.05$ & N.S. \\
\hline $\mathrm{Sb}$ & -0.480 & 1.447 & $>0.05$ & N.S. \\
\hline $\mathrm{Sc}$ & 0.017 & 0.044 & $>0.05$ & N.S. \\
\hline $\mathrm{Se}$ & 0.367 & 1.043 & $>0.05$ & N.S. \\
\hline $\mathrm{Si}$ & 0.033 & 0.087 & $>0.05$ & N.S. \\
\hline Sn & -0.610 & -2.037 & $0.1>p>0.05$ & $\begin{array}{c}\text { N.S. (Close to } \\
10 \%) .\end{array}$ \\
\hline $\mathrm{Sr}$ & 0.220 & 0.608 & $>0.05$ & N.S. \\
\hline $\mathrm{Ti}$ & -0.083 & -0.220 & $>0.05$ & N.S. \\
\hline V & 0.400 & 1.154 & $>0.05$ & N.S. \\
\hline Y & 0.183 & 0.492 & $>0.05$ & N.S. \\
\hline $\mathrm{Zn}$ & 0.550 & 1.741 & $>0.05$ & N.S. \\
\hline
\end{tabular}

Table 3.4. Pearson's correlation coefficient values form assessing the relationship top dying index value and the concentrations of various elements (in ppb). Key to symbols: N.S. = not significant, $p>0.05 ; *=$ $0.05>p>0.01, p<0.1=$ not significant, but close to fit.

\begin{tabular}{llll}
\hline Name of Elements & $\begin{array}{l}\text { Value of } \mathbf{r} \\
\text { (with 7df) }\end{array}$ & $\begin{array}{l}\text { Probability } \\
\text { (P-value) }\end{array}$ & Significance \\
\hline Nickel $(\mathrm{Ni})$ & 0.377 & 0.317 & N.S \\
Lead $(\mathrm{Pb})$ & 0.594 & 0.092 & $\mathrm{p}<0.1$ \\
Soil pH & -0.240 & 0.534 & N.S \\
Water pH & 0.307 & 0.422 & N.S \\
$\begin{array}{l}\text { Exchangeable } \\
\text { Potassium (Ex. K) }\end{array}$ & -0.022 & 0.956 & NS \\
$\begin{array}{l}\text { Exchangeable Sodium } \\
\text { (Ex. Na) }\end{array}$ & -0.367 & 0.332 & NS \\
Soluble Sodium (Na) & 0.165 & 0.672 & NS \\
Soil Sulphur(S) & -0.079 & 0.841 & NS \\
Tin (Sn) & -0.705 & 0.034 & $*(\mathrm{P}<0.05)$ \\
Zinc (Zn) & 0.532 & 0.140 & N.S \\
\hline
\end{tabular}

Conclusions about the factors

The heavy metal concentrations and other soil and water parameters tested in general did not show significant correlations with either the growth parameters for the trees or for the amount of top-dying as determined by the index of severity, although there were a few exceptions. However, there were significant differences between the compartments in a number of the parameters tested. The implications of these results, as well as those on vegetation structure and the questionnaire survey, will be discussed in the following chapter.

\section{Discussion}

In trying to assess which factors might be responsible for the problem of top-dying, particularly of Heritiera fomes trees, in the Sundarbans. In this research, particular emphasis has been placed on analysing soil samples from the study sites to determine what chemical elements were present, and their concentrations, so that the relationships between these chemical constituents and the severity of top-dying could be explored. This chapter aims to bring these various themes together, to assess what the results obtained have indicated about the possible causes of topdying, and then to indicate further work that appears necessary arising from these conclusions.

The majority of the work reported in this thesis has been on the evaluation of chemical concentrations of a range of elements in soil and water samples, with particular emphasis on the heavy metals which have been implicated in other problems in Bangladesh (such as Arsenic, Iron, and Lead in ground waters), and which might have been present in elevated concentrations in the Sundarbans because of various sources of contamination. It is particularly interesting to note that although many of the elements were present in concentrations that could be considered elevated compared to uncontaminated sites (see later in this chapter), very few of them proved to be significantly correlated with the amount of top-dying, or to vary in concentrations in a manner consistent with the plots' perceived top-dying status (assessed by ANOVA). Thus, the general conclusion that greater top-dying is directly related to elevated heavy metal contamination is not supported by the present results, although generally raised concentrations may well act as a stressor which could contribute to reduction in the health of the trees. However, there were certain specific elements and other parameters of the soil that did show a significant correlation with top-dying intensities, or which gave significant ANOVA results, or were sufficiently close to significance $(<0.10$ probability) that they are worth being highlighted for further investigation. In order to evaluate better the implications of these findings, it is necessary to give some further information about these elements, namely $\mathrm{Pb}, \mathrm{Sn}, \mathrm{Zn}$ and exchangeable $\mathrm{K}$, and also about soil $\mathrm{pH}$. The statistical result indicated is an inverse relationship, that is, the more $\mathrm{Sn}$ is present, the less top-dying there is. If 
it is presumed that this is a real result and is not simply an artefact from the statistical analyses, the implication is that either Sn directly inhibits top-dying, or that it is negatively correlated indirectly because of another factor that is linked directly with top-dying. Mangrove forests generally require a very specific physico-chemical environment to flourish, and changes in one element may have effects on general balance of that environment and affect other elements which could influence top-dying, even if the specific element is not having a direct effect on it.

A further element which has been highlighted in this research as perhaps having a direct effect on top-dying was Lead $(\mathrm{Pb})$. In this result analyses, $\mathrm{Pb}$ concentration and top-dying by Spearman's correlation coefficient was $r_{s}=$
0.51 with a probability of $\mathrm{p}<0.2$. These results indicate $\mathrm{Pb}$ was close to significance, therefore deserving further attention. Unlike the results for $\mathrm{Sn}$, here the relationship is a positive one, greater $\mathrm{Pb}$ concentration being related to more top-dying (Figure 4.2). This trend is perhaps easier to suggest an interpretation for: the increased presence of the metal weakens the trees, and allows them to be more affected by the agents of top-dying such as the pathogens. There was also a further result, close to significance $(\mathrm{p}=$ 0.056), when comparing $\mathrm{Pb}$ concentration with tree diameter by Pearson's correlation coefficient. The correlation was negative, that is greater $\mathrm{Pb}$ may lead to reduced growth of trees in their girth.

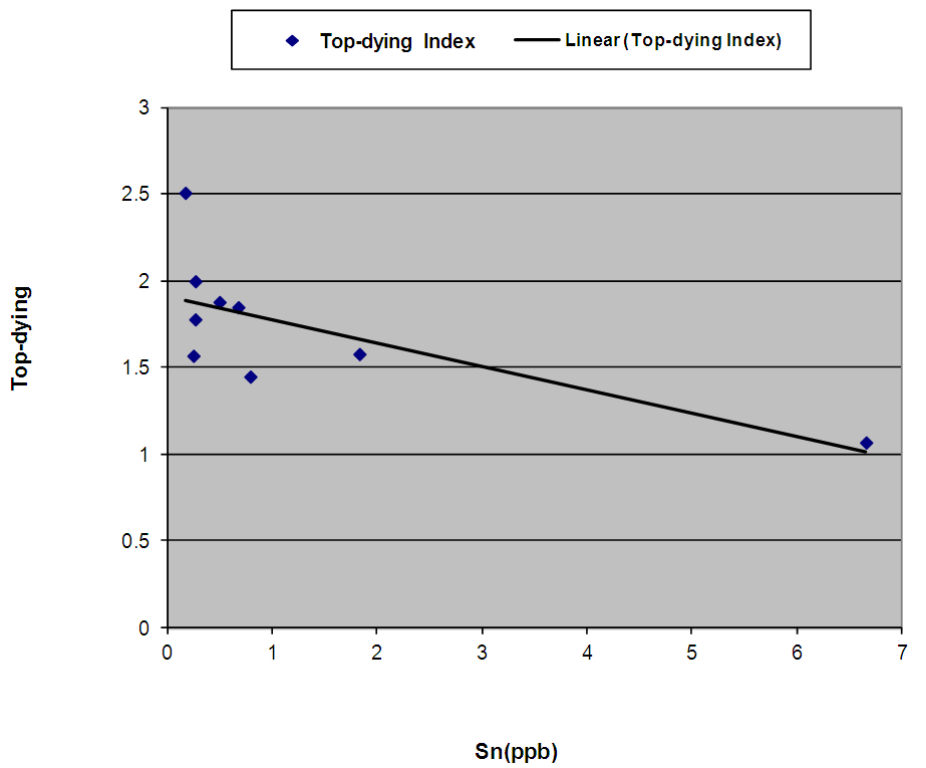

Figure 4.1. Scatter diagram shows the correlation between $S n(p p b)$ and Top-dying index values in the three compartments (26, 28 and 31) sampled in the Sundarbans, with three plots in each compartment.

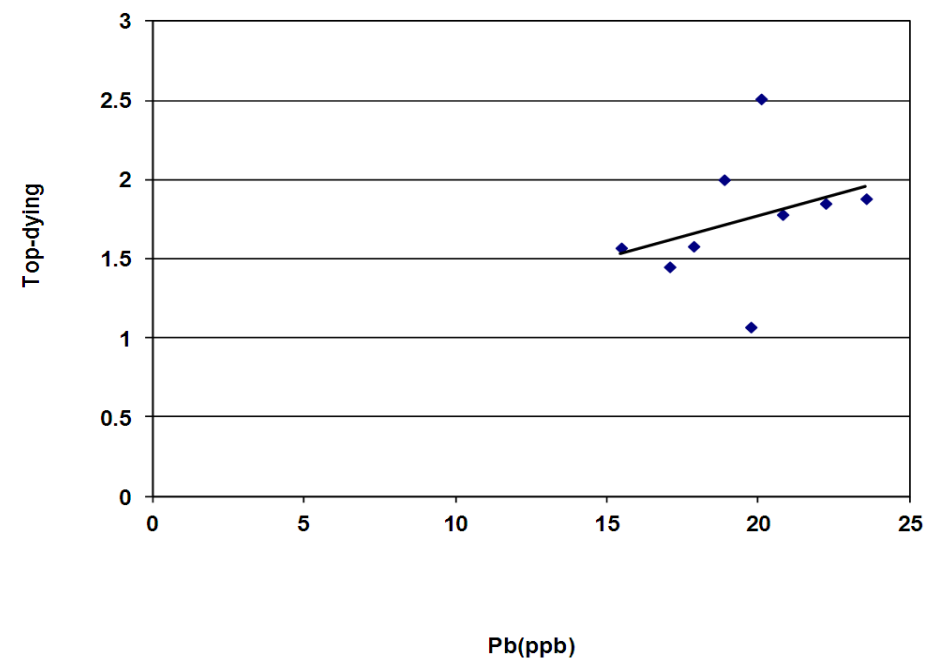

Figure 4.2. Scatter diagram shows the correlation between $\mathrm{Pb}(\mathrm{ppb})$ and Top-dying index values in the three compartments (26, 28 and 31) sampled in the Sundarbans, with three plots in each. 


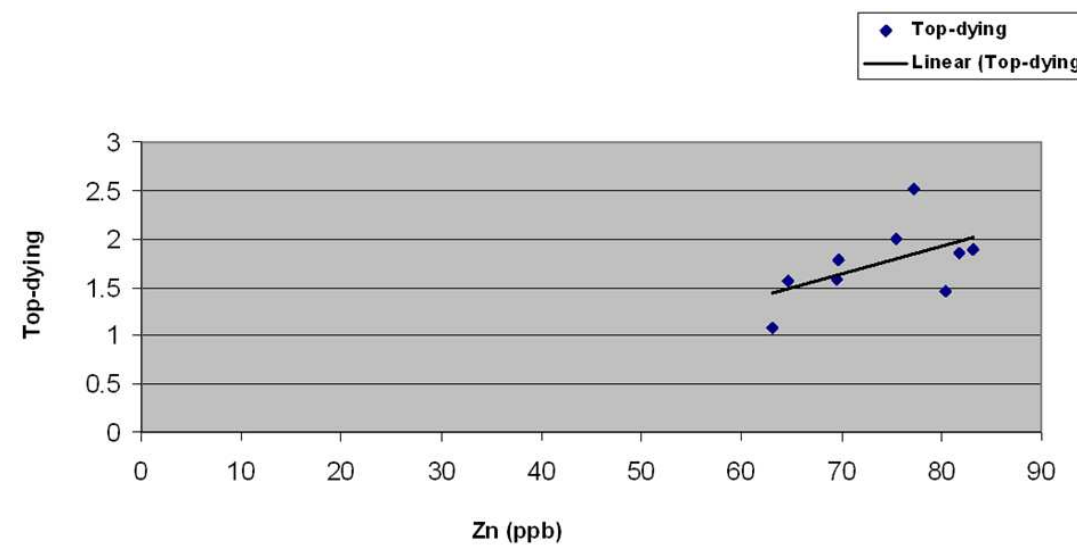

Figure 4.3. Scatter diagram shows the correlation between $\mathrm{Zn}(p p b)$ and Top-dying index values in the three compartments (26, 28 and 31) sampled in the Sundarbans, with three plots in each.

Scatter diagram shows a positive correlation between $\mathrm{Zn}$ mean concentration (ppb) and Top-dying index values in the three compartments $(26,28$ and 31) sampled in the Sundarbans, with three plots in each. However, in the present research, the Spearman's correlation coefficient test has showed a positive correlation between average $\mathrm{Zn}$ concentrations and top dying, $\left(\mathrm{r}_{\mathrm{s}}\right.$-value $\left.=0.55, \mathrm{P}>0.05\right)$. As with $\mathrm{Pb}$ therefore, greater $\mathrm{Zn}$ concentrations tend to be related to more top-dying, as shown in Figure 4.3.

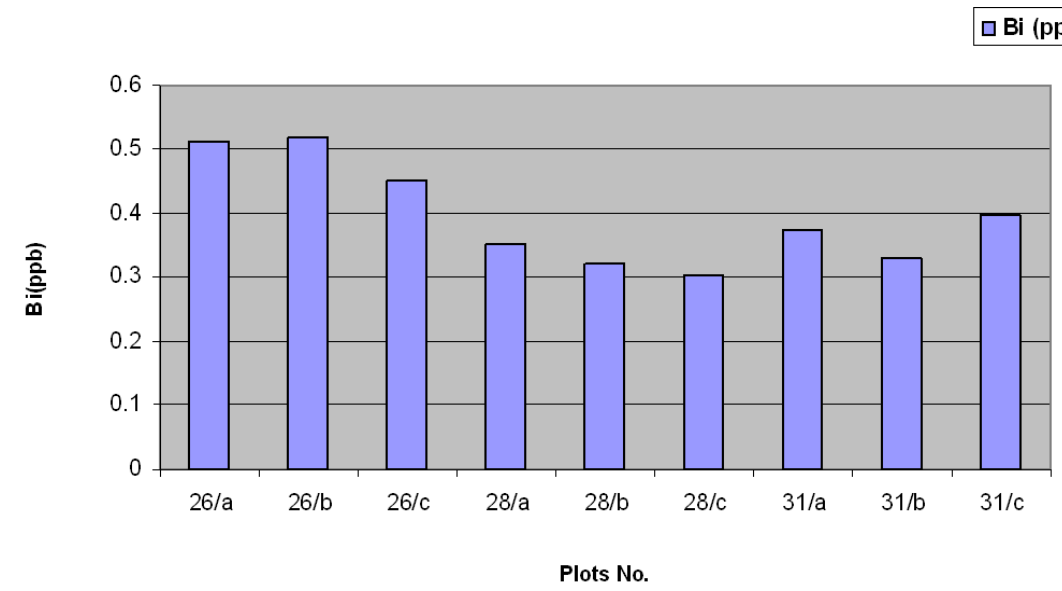

Figure 4.4. Bar chart showing the mean concentrations of Bi for each compartment and plot.

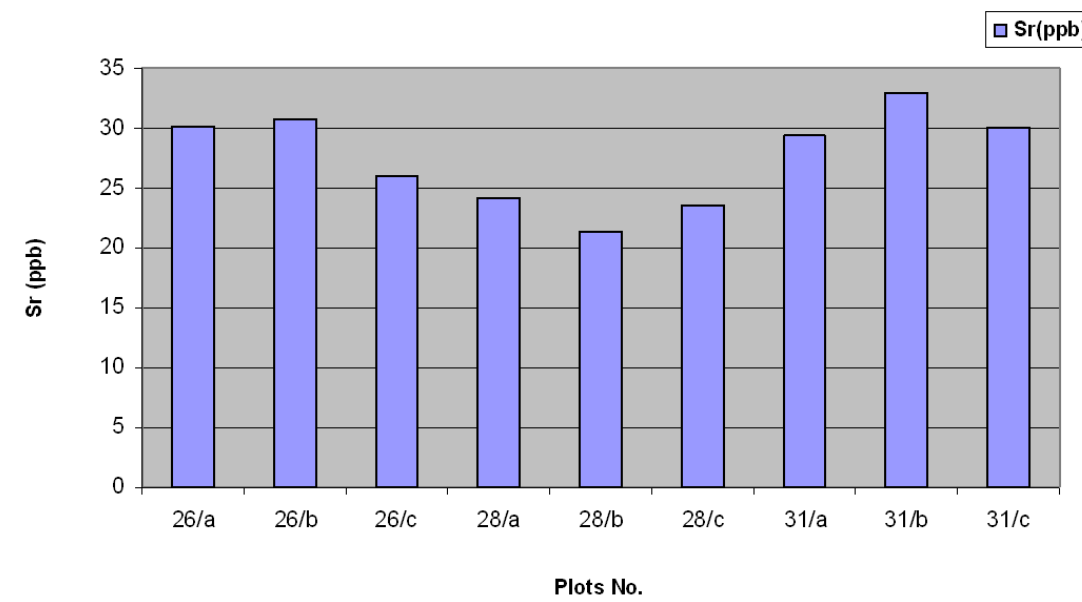

Figure 4.5. Bar chart showing the mean concentrations of Sr for each 


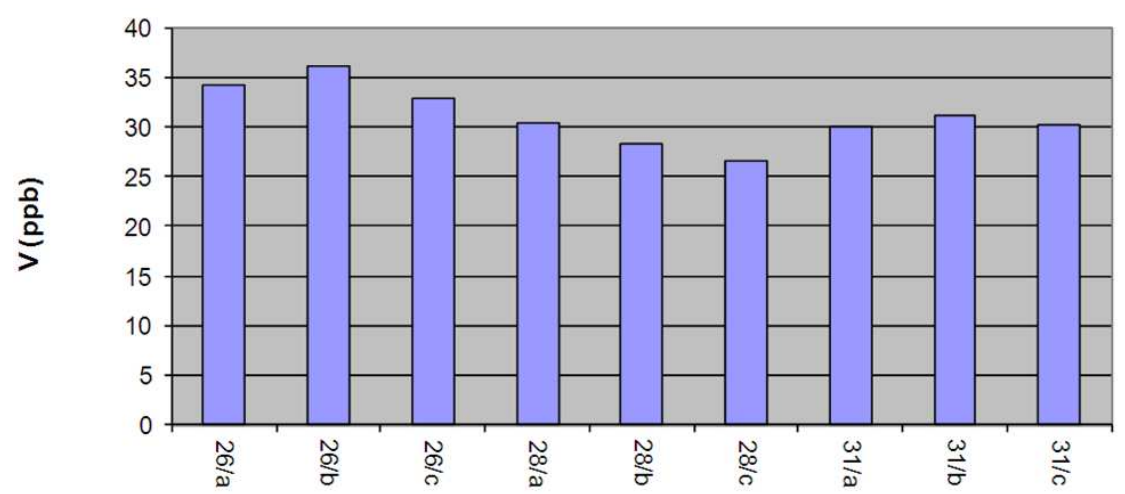

Plots No.

Figure 4.6. Bar chart showing the mean concentrations of V for each compartment and plot.

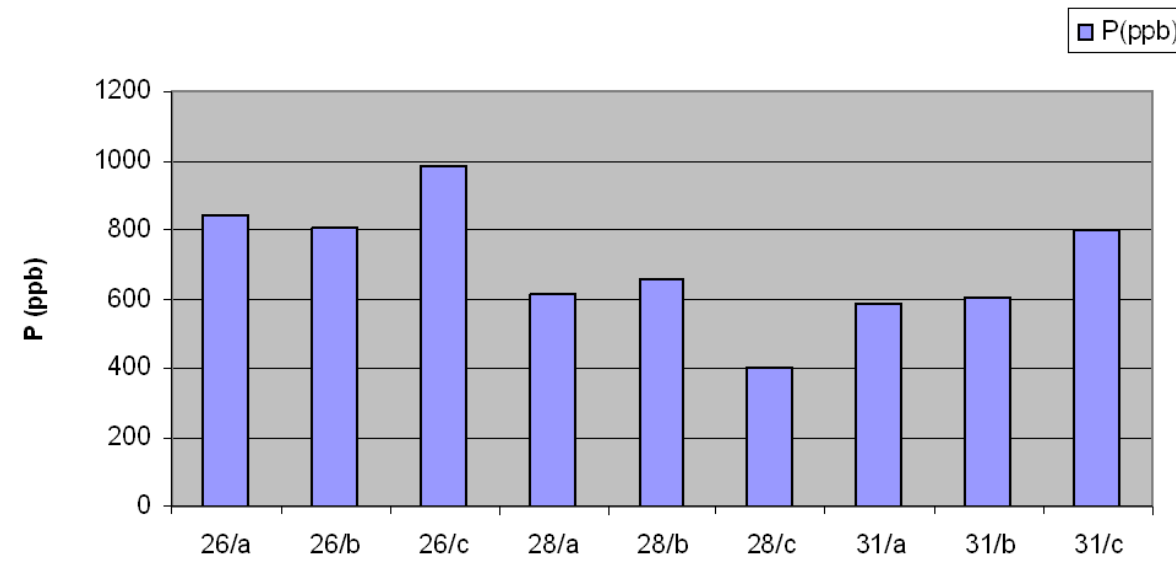

Plots No.

Figure 4.7. Bar chart showing the mean concentrations of $P$ for each compartment and plot.

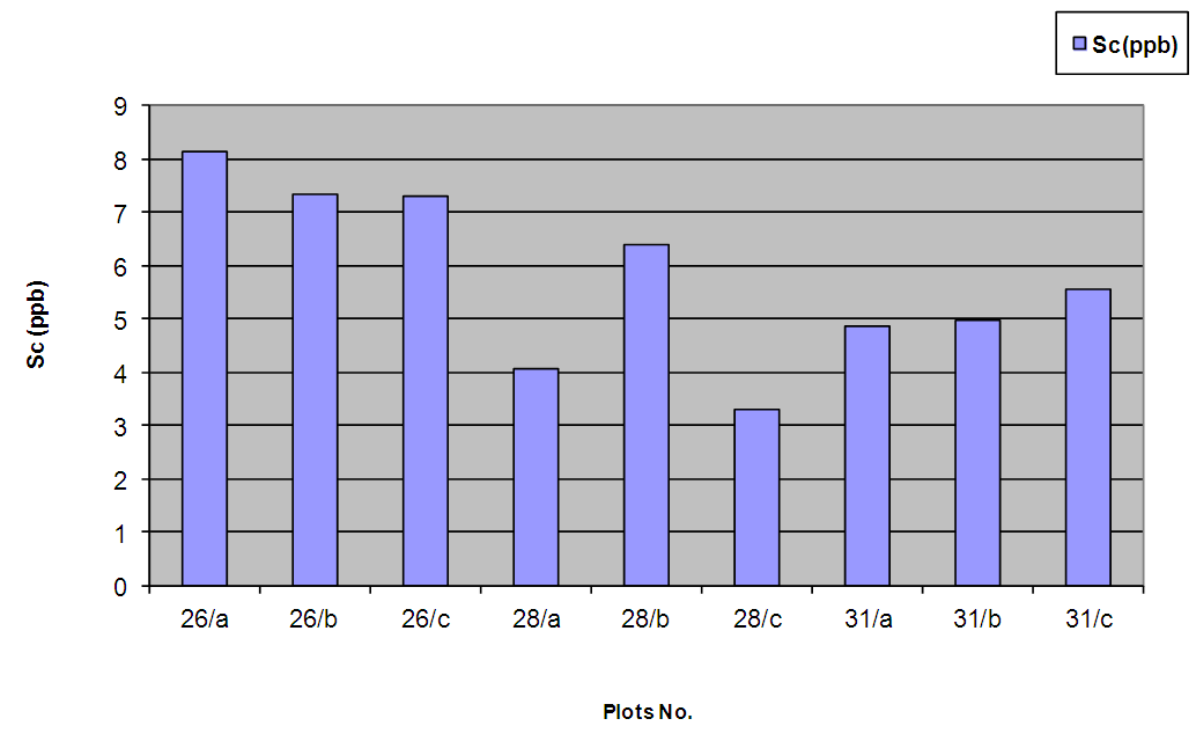

Figure 4.8. Bar chart showing the mean concentrations of Sc for each compartment and plo

Besides the heavy-metal concentrations in the soil, the result presented in 
- Exc. Kmean av. Conc. Linear (Exc. Kmean av.
Conc.)

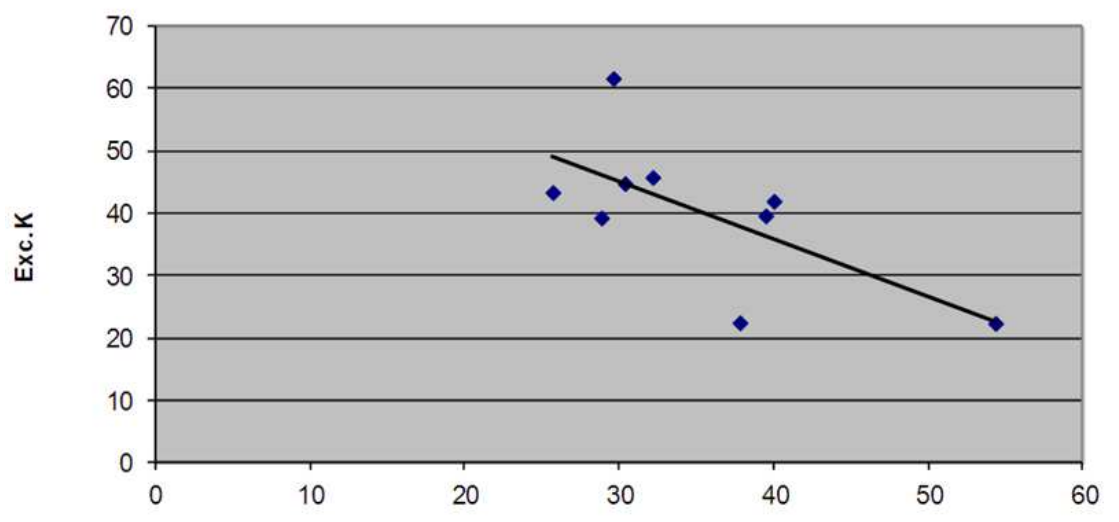

Tree diameter

Figure 4.9. Scatter diagram shows the correlation between mean average Exc. $K$ and mean average tree diameter.

\section{Conclusion}

Although there were only a few individual chemical elements which showed significant correlations with the amount of top-dying, there was evidence of elevated heavy-metal concentrations of many elements in the Sundarbans, which are likely to contribute to the increase in top-dying observed. There were also significant differences between different areas in the Sundarbans, and evidence of water supply problems to the system. Therefore, it is concluded that several factors are responsible for this increase in top-dying, rather than one specific factor only. Top-dying plots, but is consistent when comparing plots 1 and 3 in each compartment compartment 31 having the highest $\mathrm{pH}$. There were no significant variations in any of the parameters for the water samples, for compartments or for plots, although water $\mathrm{pH}$ was close to significance when comparing between plots (Table 3.4).This presumably implies that the water characteristics were quite consistent between different locations. This is, however, surprising given the significant differences in soil results in Table 3.3; for example, one might have expected water $\mathrm{Na}$ concentrations to vary in similar manner to soil $\mathrm{Na}$ values, since most of the soil $\mathrm{Na}$ has probably derived from that brought in by sea water. It is possible that soil $\mathrm{Na}$ reflects historical differences between compartments that are no longer evident in present day-water, i.e that water characteristics have changed notably in more recent periods.

\section{Final Conclusions}

Although there were only a few individual chemical elements which showed significant correlations with the amount of top-dying, there was evidence of elevated heavy-metal concentrations of many elements in the Sundarbans, which are likely to contribute to the increase in top-dying observed. There were also significant differences between different areas in the Sundarbans, and evidence of water supply problems to the system. Therefore, it is concluded that several parameters are responsible for this increase in top-dying, rather than one specific factor only.

\section{Acknowledgements}

My research work was supported financially by the Peoples' Republic of Bangladesh and the Asian Development Bank (ADB), whom I thank. Particular thanks are due to the ADB head office, Manila for their support and help. I thank sincerely Dr. W.G.H. Hale (Principal Supervisor), University of Bradford, UK, Professor Mike Ashmore (Technical Supervisor), University of York, UK and Dr. P.J. Hogarth for their advice and comments on the work; Dr. Ben Stern and the staff at the Analytical Centre, Bradford, for their help with the ICPMS analyses; Professor Sirajul Hoque, Mustafa (lab Technician)and staff at Dhaka University for providing facilities; and staff of the Forestry Service, Bangladesh Government, for field assistance. Moreover I indebted to my beloved parents ( Munshi Aowlad Hossain, Mrs. Ashrafunness), my wife (Dr. Shahanaj Khatun), my son (Munshi Tasneem Redowan), my daughter (Marwa Ashra), my beloved brothers (Munshi Abul Kalam Azad), and (Munshi Abdus Salam) and my 6 sisters (Layla Anjumand Banu (Chandu), Akter Rashida Banu (Turi), Saleha Pervin (Lili), Azmeri Ferdowsi (Dolly), Jannatul Ferdowsi (Polly) and my beloved youngest sister Bedowra Ferdowsi (Jolly) as well as all family members for their inspiration and help. 


\section{References}

[1] Awal, M.A. (2007). Analysis of possible environmental factors causing top-dying in mangrove forest trees in the Sundarbans in Bangladesh. $\mathrm{PhD}$ thesis, University of Bradford.

[2] Awal, M.A., Hale, W.H.G. \& Stern, B. (2009). Trace element concentrations in mangrove sediments in the Sundarbans, Bangladesh. Marine Pollution Bulletin, 58(12), 1944-1948.

[3] Awal, M.A. (2014). "Correlation between the chemical composition of the surface sediment and water in the mangrove forest of the Sundarbans, Bangladesh, and the regeneration, growth and dieback of the forest trees and people health"..Journal of Science Innovation; 2014. 2(2): pp.11-21.Science Publishing Group, USA; May 20th, 2014(2):11-21;doi: 10.11648/j/si.20140202.11.

[4] Anonymous, 1975. Under-exploited tropical plants with promising economic value. National Academy of Sciences, Washington.

[5] BFRI, 1990-95. Annual Research Report. Silviculture Genetics Division. Bangladesh Forest Research Institute (BFRI), Chittagong, Bangladesh.

[6] Bhuyan, A. A. 1994. Draft final report of the soil scientist. FAO / UNDP Project-Integrated Resource development of the Sundarbans Reserved Forest, Khulna, Bangladesh, 124 pp.

[7] Burns, K.A; S. D. Garrity, and S.C. Levings. 1993. How many years until mangrove ecosystems recover from catastrophic spills? Marine Pollution Bulletin 26 (5): 239 248

[8] Chaffey, D. R; Miller, F.R; Sandom, J. H. 1985. A forest inventory of the Sundarbans, Bangladesh, Main report, Project Report No.140, 196 pp; Overseas Development Administration, London, U.K:195-196.

[9] Chaudhury, A.M. (1962). Working Plan of Sundarbans Forest Division, for the period from 1960-61 to 1979-80, Vol I, II, and III. Forest Department.

[10] Chaudhury, A.M. 1968. Working Plan of Sundarbans Forest Division for the period from 1960-61 to 1979-80, 82: East Pakistan Government Press, Dacca.

[11] Chowdhury, J. H. 1973. Preliminary report of the investigation of the top dying of Sundri in the Sundarbans. BFRI, Chittagong, Bangladesh, 2 p.

[12] Dyer, K.R. (1986). Coastal and estuarine sediment dynamics. John Wiley \& Sons, Chichester.

[13] Faizuddin, M. and Islam, S.A. 2003. Generated Technology and Usable Information of the Mangrove Silviculture. Mangrove Silviculture Division, Bangladesh Forest Research Institute

[14] FAO, 1994. Review of the state of world marine fisheries resources. FAO Fisheries resources. FAO Fisheries Technical Approach Paper 335:143.
[15] Fujimoto, K; Miyagi, T; Kikuchi, T; and kawana, T. (1996). Mangrove habitat formation and response to Holocene sealevel changes on kosrae Island, Micronesia. Mangrove and salt marshes, 1:47-57.

[16] Gopal, B. \& Chauhan, M. (2006) Biodiversity and its conservation in the Sundarban mangrove ecosystem. Aquatic Sciences, 68(3), 338-354.

[17] Hassan, M. M. 1984. Soil formation in the recent deltaic region of Bangladesh. Bangladesh Journal of Soil Science 20:37-45.

[18] Islam, M.L., Alam, M.J., Rheman, S., Ahmed, S.U. \& Mazid, M.A. (2003, 2004). Water quality, nutrient dynamics and sediment profile in shrimp farms of the Sundarbans mangrove forest, Bangladesh. Indian Journal of Marine Sciences, 33, 170-176.

[19] Jones, G; Battershill, C; and Cole, R. (1992). Marine reserves: do they work? In: C. Battershill (ed.) Proceedings of the International Temperate Reef Symposium, Aucland, New Zealand, p.29-45.

[20] Karim, A. March 1994. Mangrove Silviculture-Volume 13. FAO/UNDP (IRDP): 38-140.

[21] Sokal, R.R. and Rohlf, F.J. (1981). Biometry. San Francisco, W.H. Freeman.

[22] Tamang, K. M. 1993. Wildlife Management Plan for the Sundarbans Reserved Forest. Integrated Resource Development of the Sundarbans Reserve Forest. UNDP /FAO, BGD/84/056, Khulna, Bangladesh.

[23] Tiner, R. W; J R. (1984). Wetlands of the United States: Current Status and Recent Trends. Newton Corner, Massachusetts: U.S. Fish and Wildlife Service, Habitat Resources.

[24] Troup, R.S. 1921. The Silviculture of Indian TreesVolume 1. Clarendon Press, Oxford: 153-544.

[25] UN-ESCAP, 1987. Final Report: Volume 2. Coastal environment management plan for Bangladesh. Bangkok, Thailand.

[26] UN-ESCAP, 1988. Coastal environment management plan for Bangladesh. Bangkok, Thailand: 7-34.

[27] UN-ESCAP, 1988. Coastal environment management plan for Bangladesh. Bangkok, Thailand: 7-34.

[28] UNESCO, 1997. Convention Concerning the Protection of the World Cultural and Natural Heritage, France, Paris.

[29] UN-ESCAP (1987). Final Report: Volumen 2. Coastal environment management plan for Bangladesh, Bangkok, Thailand. UN-ESCAP (1988). Coastal environment management plan for Bangladesh. Bangkok, Thailand, pp. 7-34.

[30] WHO, 1981. Resistance of Disease vectors to pesticides. World Health Organisation, Chronicle, 35, 143.

[31] WFB, 2006. The world fact book-Bangladesh. Population of Bangladesh, Wild Fact Book: 2-3. 